Volume 4 Issue 1(2021) 18-24
Longda Xiokan:

\title{
Analisis Kebutuhan Materi Mata Kuliah Shangwu Kouyu Untuk mahasiswa Pendidikan Bahasa Mandarin UNNES
}

\section{Septiana Nur Azizah ${ }^{\bowtie}$, Anggraeni Anggraeni, Dyah Prasetiani, Ria Riski Marsuki}

Prodi Pendidikan Bahasa Mandarin, Jurusan Bahasa dan Sastra Asing, Fakultas Bahasa dan Seni, Universitas Negeri Semarang, Indonesia

\section{Info Artikel \\ Keywords: \\ Ineeds analysisi, material, \\ shangwu kouyu}

\begin{abstract}
Abstrak
Prodi pendidikan bahasa Mandarin Universitas Negeri Semarang membuka mata kuliah shangwu kouyu (percakapan bisnis) untuk mempersiapkan mahasiswanya bekerja di bidang bisnis, mengingat banyaknya proyek Tiongkok yang dinaungi di Indonesia. Agar materi yang dipelajari sesuai dengan apa yang dibutuhkan dilapangan, perlu adanya analisis untuk mengetahui kebutuhan materi shangwu kouyu, sehingga bisa benar benar diaplikasikan setelah lulus nantinya. Tujuan penelitian ini adalah untuk mengetahui kebutuhan materi menurut dosen, stake holder, alumni dan mahasiswa. Penelitian ini menggunakan metode deskriptif - kualitatif. Teknik pengumpulan data menggunakan teknik wawancara dan kuesioner. Teknik analisis data menggunakan teknik analisis data kualitatif yang bersumber dari Miles dan Huberman. Hasil penelitian ini adalah sebagai berikut: (1) mahasiswa membutuhkan bahan ajar dengan materi komprehensiv tingkat menengah dan sesuai dengan kebutuhan lapangan kerja yang sebenarnya (2) ada 8 materi yang paling dibutuhkan menurut stake holder, yaitu materi kunjungan pabrik, materi pertemuan, materi telepon bisnis, materi kontrak kerjasama, materi bersosisalisai, materi acara bisnis, materi perdagangan dan materi surat bisnis. (3) ada 5 materi yang paling dibutuhkan menurut alumni, , yaitu materi metode pembayaran materi pengiriman barang, materi pengemasan barang, materi ekspor impor, dan materi kontrak kerjasama dan 2 materi tambahan yaitu pajak dan produksi, (4) ada 5 materi yang paling dibutuhkan menurut mahasiswa, yaitu materi tentang kontrak kerjasama, materi bersosialisasi, materi telepon bisnis, materi ekspor impor serta materi tentang pemasaran dan layanan pelanggan.
\end{abstract}

Abstract

The Chinese language education study program, Semarang State University, opens the shangwu kouyu (business conversation) course to prepare students to work in the business field, considering the many Chinese projects that are shaded in Indonesia. In order for the material to be studied in accordance with what is needed in the field, there needs to be an analysis to find out the material needs of shangwu kouyu, so that it can really be applied after graduation. The purpose of this study was to find out the material needs according to lecturers, stake holders, alumni and students. This study used descriptive qualitative method. Data collection techniques using interview techniques and questionnaires. Data analysis techniques used qualitative data analysis techniques sourced from Miles and Huberman. The results of this study are as follows: (1) students need teaching materials with intermediate level comprehensive material and are in accordance with actual job field needs, (2) There are 8 materials that are most needed according to stakeholders, namely factory visit materials, meeting materials, business phone calls, cooperation contract materials, materials on business events, trade materials and business letter materials. (3) there are 5 materials that are most needed according to alumni, namely payment method materials for goods delivery, packaging materials, export-import materials, and cooperation contract materials and 2 additional materials, namely tax and production, (4) there are 5 materials that are the most required according to students, namely material on cooperation contracts, socializing materials, business telephone materials, export-import materials as well as materials on marketing and customer service.

Alamat korespondensi:

Gedung B9 Lantai 2 FBS UNNES

P-ISSN 2528-5734

E-ISSN 2715-1611

Kampus Sekaran, Gunungpati, Semarang, 50229

E-mail: septiananurazizah19@gmail.com 


\section{PENDAHULUAN}

Mempelajari bahasa Mandarin yang merupakan bahasa internasional kedua setelah bahasa Inggris bukan lagi hal yang sulit ditemukan di Indonesia. bahkan bahasa Mandarin sudah dijadikan sebagai mata pelajaran di banyak sekolah swasta dan beberapa sekolah negeri. Di sekolah negeri maupun swasta, baik tingkat dasar maupun tingkat tinggi, siswa akan dipersiapkan agar dapat menguasai bahasa Mandarin baik secara lisan maupun tulisan, sehingga akan menciptakan lulusan lulusan yang kompeten. Karena nantinya, mereka akan memenuhi kebutuhan lapangan kerja, baik sektor pemerintah maupun swasta.

Menurut data Badan Koordinasi Penanaman Modal (BKPM) mengenai realisasi investasi pada kuartal II tahun 2017, Tiongkok menduduki posisi ketiga setelah Singapura dan Jepang sebagai investor terbesar yang menanamkan modalnya di Indonesia dengan realisasi investasi senilai USD 1.355,66 juta. Dengan tingginya nilai investasi yang ditanamkan oleh Tiongkok serta banyaknya proyek yang dinaungi di Indonesia, tentu saja kemudian muncul suatu kebutuhan akan tenaga kerja yang mampu dan ahli dalam berbahasa Mandarin, yang mana tenaga ahli tersebut nantinya memiliki peran penting dalam membangun jembatan komunikasi antara investor, pengusaha serta kolega bisnis. Hal ini membuktikan bahwa tenaga ahli yang memiliki kemampuan berbahasa Mandarin memiliki peluang tinggi untuk dapat bersaing dalam dunia kerja. Untuk itu, dasar pembelajaran dan pembekalan yang efektif serta tepat sasaran kepada mahasiswa pada masa perkuliahan merupakan hal yang penting.

Di prodi pendidikan bahasa Mandarin Universitas Negeri Semarang mahasiswa disiapkan untuk menjadi tenaga pendidik, namun mahasiswa juga diberikan beberapa mata kuliah pilihan sebagai bekal untuk terjun ke dunia kerja, salah satunya mata kuliah shangwu kouyu (berbicara bisnis).

Mata kuliah shangwu kouyu ini adalah mata kuliah yang mengajarkan mahasiswanya hal hal terkait dengan bisnis. Dengan adanya mata kuliah ini, mahasiswa seharusnya lebih percaya diri untuk menerima tawaran pekerjaan dibidang bisnis. Akan tetapi pada kenyataannya, hanya sedikit mahasiswa yang memiliki kepercayaan diri untuk menerima tawaran kerja dibidang bisnis. Hal ini dikarenakan materi yang dipelajari dalam pembelajaran shangwu kouyu sebatas kunjungan pabrik, kegiatan rapat dan menawarkan produk.

Berdasarkan hasil penelusuran alumni mahasiswa prodi pendidikan bahasa Mandarin Universitas Negeri Semarang yang dilaksanakan pada pertengahan tahun 2019, menunjukan hasil yang menyatakan bahwa sebanyak $31,5 \%$ alumni membutuhkan mata kuliah shangwu kouyu untuk membantu pekerjaanya. Peneliti juga melakukan wawancara kepada beberapa alumni yang bekerja di perusahaan China, mereka mengatakan bahwa kendala yang ia dapati sebelum mulai bekerja adalah keharusan memahami tentang istilah - istilah baru terkait pekerjaannya dengan cepat.

Untuk meminimalisir hal tersebut, pembelajaran shangwu kouyu selama masa perkuliahan seharusnya memuat materi materi yang dapat dijadikan bekal mahasiswanya ketika akan bekerja di bidang bisnis. Sebagai mata kuliah pilihan, shangwu kouyu mengajarkan materi yang cukup untuk masuk ke dunia bisnis. Bahan ajar yang digunakan di prodi pendidikan bahasa Mandarin UNNES dalam dua sks pembelajaran shangwu kouyu selama satu semester adalah buku terbitan Peking University Press tahun 2009 yang berjudul 新丝路 - 中级速 成商务汉语 II (xīnsīlù - zhōngjí sùchéng shāngwù hànyǔ II). Terdapat beberapa materi dalam bahan ajar ini, akan tetapi hanya tiga materi yang berhasil dipelajari dalam satu semester pertemuan di kelas.

Dalam buku SITUATIONAL CHINESE Business and Business Travel yang ditulis oleh 孫 雅玲 (Sun Ya Ling), dkk tahun 2010, terdapat beberapa tema materi yang perlu dipelajari seseorang untuk mempersiapkan diri bekerja di perusahaan China. Tema tema tersebut yaitu, 
1. Bisnis Perjalanan (商务旅行)

2. Bersosialisasi (社交)

3. Konferensi (会议)

4. Acara Bisnis (商业活动 )

5. Perdagangan (贸易)

6. Pemasaran Dan Layanan Pelanggan (市 场营销和客户服务）

\section{Frasa Tempat Kerja Umum (职场常用} 短语）

\section{Perekrutan (招聘)}

Untuk mengetahui materi yang paling dibutuhkan untuk dipelajari mahasiswa prodi pendidikan bahasa Mandarin UNNES, perlu adanya analisis kebutuhan materi mata kuliah shangwu kouyu. Agar apa yang dipalajari mahasiswa dapat benar benar diaplikasikan setelah lulus nantinya. Tujuan dari penelitian adalah (1) Untuk mengetahui gambaran materi mata kuliah shangwu kouyu prodi pendidikan bahasa Mandarin Universitas Negeri Semarang (2) Untuk mendeskripsikan hasil wawancara dengan dosen prodi pendidikan bahasa Mandarin Universitas Negeri Semarang (3) Untuk mendeskripsikan hasil pengisian angket oleh stake holder dalam bidang bisnis (4) Untuk mendeskripsikan hasil pengisian angket oleh mahasiswa alumni prodi pendidikan bahasa Mandarin Universitas Negeri Semarang yang bekerja dalam bidang bisnis (5) Untuk mendeskripsikan hasil pengisian angket oleh mahasiswa prodi pendidikan bahasa Mandarin Universitas Negeri Semarang.

\section{METODE}

Metode yang digunakan dalam penelitian ini adalah metode deskriptif dengan pendekatan kualitatif. Pendekatan kualitatif adalah suatu proses penelitian dan pemahaman yang berdasarkan pada metodologi yang menyelidiki suatu fenomena sosial dan masalah manusia. Siyoto ( 2010:17). Penelitian dengan metode ini akan menghasilkan data deskriptif berupa katakata tertulis, ucapan maupun perilaku dari responden yang diamati. Teknik pengumpulan data yang digunakan dalam penelitian ini adalah wawancara, dan kuesioner. Teknik analisis data dalam penelitian ini menggunakan model Analysis Interactive dari Miles dan Huberman, yang membagi kegiatan analisis menjadi beberapa bagian, yaitu : pengumpulan data, reduksi data, penyajian data dan penarikan kesimpulan atau verifikasi data. Ilyas ( 2015:94 )

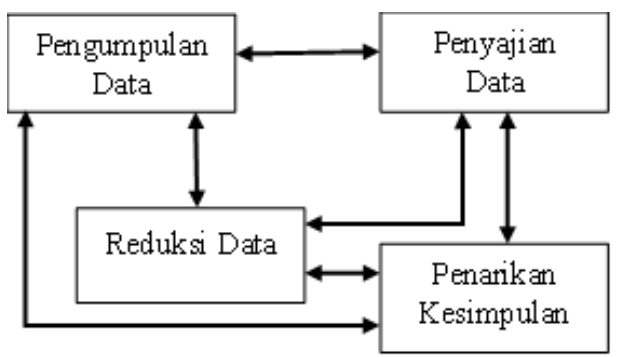

Gambar 1. Analysis Interactive Model dari Miles \& Huberman

Teknik yang digunakan untuk memeriksa keabsahan data dalam penelitian ini adalah triangulasi. Triangulasi menurut Saebani ( 2008:189) adalah teknik pengumpulan data yang bersifat menggabungkan beberapa teknik pengumpulan data dan sumber data yang telah ada.

Moloeng (dalam Wildia, dkk 2018:8 ) membagi teknik pemeriksaan keabsahan data ini kepada tiga, yaitu triangulasi sumber, triangulasi metode/teknik dan triangulasi teori. Pada penelitian ini, peneliti menggunakan triangulasi sumber untuk memperoleh keabsahan data. Menurut Sugiyono ( 2011:330 ) triangulasi sumber yaitu mendapatkan data dari sumber yang berbeda-beda dengan teknik yang sama.

\section{HASIL DAN PEMBAHASAN}

Hasil penelitian ini meliputi tiga hal, yaitu: (1) hasil wawancara dengan dosen program studi pendidikan bahasa Mandarin Universitas Negeri Semarang dan, (2) hasil analisis angket kebutuhan materi mata kuliah shangwu kouyu dari tiga responden yaitu stake holder, alumni mahasiswa program studi pendidikan bahasa Mandarin Universitas Negeri Semarang dan mahasiswa program studi pendidikan bahasa Mandarin Universitas Negeri Semarang. 
Hasil wawancara dengan dosen program studi pendidikan bahasa Mandarin Universitas Negeri Semarang

Berdasarkan hasil wawancara yang dilakukan dengan dosen mata kuliah shangwu kouyu, dapat disimpulkan bahwa shangwu kouyu sebagai mata kuliah pilihan sangat penting untuk diberikan kepada mahasiswa, karena setelah lulus nantinya tidak semua mahasiswa ingin menjadi guru. Beberapa dari mereka mungkin ingin bekerja di perusahaan China, hal ini sangat mungkin terjadi melihat banyaknya perusahaan China yang berdiri di Indonesia dan membutuhkan tenaga kerja yang mampu berbahasa Mandarin dengan baik.

Dalam pembelajaran shangwu kouyu selama ini, dosen mata kuliah shangwu kouyu menyatakan bahwa bahan ajar yang digunakan dalam pembelajaran saat ini masih kurang, dan belum menemukan bahan ajar yang tepat untuk diberikan kepada mahasiswa. Ia berharap bahan ajar yang nantinya di gunakan dalam pembelajaran shangwu kouyu memuat materi komprehensiv tingkat menengah dan sesuai dengan kebutuhan lapangan yang sebenarnya, serta sesuai dengan keterbaruan perkembangan zaman, sehingga ketika lulus nantinya mahasiswa sudah memiliki bekal yang sangat cukup.

Hasil analisis angket kebutuhan materi mata kuliah shangwu kouyu

Untuk memperoleh data yang sesuai dengan kebutuhan mahasiswa, peneliti melakukan penyebaran angket/kuisioner kepada satu orang stakeholder yaitu bapak Wuduanyu kepala kantor di perusahaan Sinohydro 中国水电 , 10 orang alumni mahasiswa pendidikan bahasa Mandarin UNNES yang bekerja di bidang bisnis dan 38 orang mahasiswa pendidikan Bahasa Mandarin UNNES

\section{Hasil Analisis Angket Kebutuhan Materi Mata Kuliah Shangwu Kouyu Menurut Stake holder}

Stake holder menyatakan bahwa diperusahaannya diperlukan orang yang dapat berbahasa Mandarin untuk menjadi penerjemah, pegawai kantor dan koordinasi eksternal. Dan untuk menempati posisi pekerjaan tersebut paling tidak orang tersebut mampu untuk menulis, berbicara dan mendengar bahasa Mandarin dengan baik. Selain itu, stake hoder juga menyatakan sangat perlu mempelajari shangwu kouyu untuk dapat bergabung dengan perusahaannya.

Tabel 1. Materi sesuai dengan bahan ajar

\begin{tabular}{|c|c|c|c|c|}
\hline \multirow{2}{*}{ NO } & \multirow{2}{*}{ MATERI } & \multicolumn{3}{|c|}{ Hasil } \\
\hline & & B & CB & TB \\
\hline 1. & $\begin{array}{l}\text { Kunjungan } \\
\text { pabrik }\end{array}$ & $\sqrt{ }$ & & \\
\hline 2. & Pertemuan & $\sqrt{ }$ & & \\
\hline 3. & Tentang produk & & $\sqrt{ }$ & \\
\hline 4. & Profil perusahaan & & $\sqrt{ }$ & \\
\hline 5. & $\begin{array}{c}\text { Pengiriman } \\
\text { barang }\end{array}$ & & $\sqrt{ }$ & \\
\hline 6. & $\begin{array}{c}\text { Metode } \\
\text { pembayaran }\end{array}$ & & $\sqrt{ }$ & \\
\hline 7. & $\begin{array}{l}\text { Pengemasan } \\
\text { barang }\end{array}$ & & & $\sqrt{ }$ \\
\hline 8. & Telepon bisnis & $\sqrt{ }$ & & \\
\hline 9. & Ekspor impor & & $\sqrt{ }$ & \\
\hline 10. & $\begin{array}{l}\text { Kontrak } \\
\text { Kerjasama }\end{array}$ & $\sqrt{ }$ & & \\
\hline 11. & Bisnis perjalanan & & & $\sqrt{ }$ \\
\hline 12. & Bersosialisasi & $\sqrt{ }$ & & \\
\hline 13. & Acara bisnis & $\sqrt{ }$ & & \\
\hline 14. & Perdagangan & $\sqrt{ }$ & & \\
\hline 15. & $\begin{array}{c}\text { Pemasaran dan } \\
\text { layanan } \\
\text { pelanggan }\end{array}$ & & & $\sqrt{ }$ \\
\hline 16. & $\begin{array}{l}\text { Frasa tempat } \\
\text { kerja umum }\end{array}$ & & & $\sqrt{ }$ \\
\hline 17. & Perekrutan & & $\sqrt{ }$ & \\
\hline 18. & Surat bisnis & $\sqrt{ }$ & & \\
\hline 19. & $\begin{array}{l}\text { Membangun } \\
\text { hubungan bisnis }\end{array}$ & & $\sqrt{ }$ & \\
\hline 20. & Jaminan & & $\sqrt{ }$ & \\
\hline 21. & Perbankan & & $\sqrt{ }$ & \\
\hline 22. & Kredit & & $\sqrt{ }$ & \\
\hline 23. & $\begin{array}{c}\text { Jenis organisasi } \\
\text { bisnis }\end{array}$ & & $\sqrt{ }$ & \\
\hline
\end{tabular}

Berdasarkan hasil analisis tabel 1. diatas, dapat disimpulkan bahwa materi kunjungan pabrik, materi pertemuan, materi telepon bisnis, materi kontrak kerjasama, materi bersosisalisai, materi acara bisnis, materi perdagangan dan materi surat bisnis dibutuhkan dalam menjalankan profesi di sebuah perusahaan China, sehingga materi materi tersebut perlu 
disiapkan sebelum benar benar bekerja di sebuah perusahaan China.

\section{Hasil Analisis Angket Kebutuhan Materi Mata Kuliah Shangwu Kouyu Menurut Alumni}

Dari 10 alumni program studi pendidikan bahasa Mandarin yang menjadi responden, 5 alumni saat ini menjalani profesi sebagai penerjemah di perusahaan China, 2 alumni berprofesi sebagai purchasing staff sekaligus penerjemah, 1 alumni berprofesi sebagai staff PPIC (perencanaan), 1 alumni berprofesi sebagai asisten general manajer dan 1 alumni lainnya berprofesi sebagai sales Manager.

Mereka menyatakan bahwa untuk bekerja di perusahaan China, kemampuan berbicara bahasa Mandarin sangat diperlukan untuk mendukung profesi ketika bekerja di perusahaan China. Mempelajari shangwu kouyu yang memang mengajarkan percakapan bisnis, melatih mahasiswa terbiasa mengucapkan bahasa bahasa bisnis yang tidak didapat pada mata kuliah lain yang disiapkan untuk menjadi tenaga pendidik.

Selain itu, alumni juga menyatakan ada beberapa kemampuan lain yang dapat mendukung profesi ketika bekerja di perusahaan China, seperti kemampuan berbahasa Inggris, kemampuan mengoperasikan komputer, kemampuan membuat rencana produksi dan kemampuan dalam bidang management.

Tabel 2. Materi sesuai dengan bahan ajar

\begin{tabular}{|c|c|c|c|c|}
\hline \multirow{2}{*}{ NO } & \multirow{2}{*}{ MATERI } & \multicolumn{3}{|c|}{ Hasil } \\
\hline & & $\mathbf{B}$ & CB & TB \\
\hline 1. & $\begin{array}{c}\text { Kunjungan } \\
\text { pabrik }\end{array}$ & 4 & 5 & 1 \\
\hline 2. & Pertemuan & 7 & 3 & - \\
\hline 3. & Tentang produk & 7 & 2 & 1 \\
\hline 4. & Profil perusahaan & 5 & 3 & 2 \\
\hline 5. & $\begin{array}{c}\text { Pengiriman } \\
\text { barang }\end{array}$ & 9 & 1 & - \\
\hline 6. & $\begin{array}{c}\text { Metode } \\
\text { pembayaran }\end{array}$ & 10 & - & - \\
\hline 7. & $\begin{array}{l}\text { Pengemasan } \\
\text { barang }\end{array}$ & 9 & 1 & - \\
\hline 8. & Telepon bisnis & 5 & 4 & 1 \\
\hline 9. & Ekspor impor & 9 & 1 & - \\
\hline 10. & $\begin{array}{l}\text { Kontrak } \\
\text { Kerjasama }\end{array}$ & 9 & 1 & - \\
\hline 11. & Bisnis perjalanan & 6 & 4 & - \\
\hline 12. & Bersosialisasi & 7 & 3 & - \\
\hline
\end{tabular}

\begin{tabular}{|c|c|c|c|}
\hline 13. & Acara bisnis & 4 & 6 \\
\hline 14. & Perdagangan & 9 & 1 \\
\hline 15. & $\begin{array}{c}\text { Pemasaran dan } \\
\text { layanan } \\
\text { pelanggan }\end{array}$ & 8 & 2 \\
\hline 16. & $\begin{array}{l}\text { Frasa tempat } \\
\text { kerja umum }\end{array}$ & 4 & 5 \\
\hline 17. & Perekrutan & 5 & 5 \\
\hline 18. & Surat bisnis & 8 & 1 \\
\hline 19. & $\begin{array}{c}\text { Membangun } \\
\text { hubungan bisnis }\end{array}$ & 7 & 2 \\
\hline 20. & Jaminan & 5 & 4 \\
\hline 21. & Perbankan & 5 & 4 \\
\hline 22 . & Kredit & 5 & 3 \\
\hline 23 & $\begin{array}{c}\text { Jenis organisasi } \\
\text { bisnis }\end{array}$ & 4 & 5 \\
\hline
\end{tabular}

Berdasarkan hasil analisis tabel 2. diatas, paling banyak alumni menyatakan bahwa materi mengenai metode pembayaran sangat dibutuhkan, selain itu materi tentang pengiriman barang, pengemasan barang, ekspor impor, dan kontrak kerjasama juga tidak kalah dibutuhkannya untuk diajarkan. Selain itu alumni juga menyarankan materi tentang pajak dan materi produksi untuk dapat diajarkan kepada mahasiswa.

\section{Hasil Analisis Angket Kebutuhan Materi Mata Kuliah Shangwu Kouyu Menurut Mahasiswa}

Paling banyak mahasiswa belajar bahasa Mandarin karena memiliki ketertarikan terhadap bahasa asing, namun tidak sedikit pula mahasiswa yang belajar bahasa Mandarin karena percaya bahwa peluang kerja yang di tawarkan untuk orang orang yang mampu berbahasa Mandarin saat ini sangat banyak.

Setelah lulus dari prodi pendidikan bahasa Mandarin UNNES nantinya, kebanyakan mahasiswa ingin menjadi pengajar. Hal ini sangat wajar karena pada dasarnya mahasiswa yang mengambil program studi pendidikan bahasa Mandarin di Universitas Negeri Semarang memang disiapkan menjadi seorang tenaga pendidik. Namun tidak menutup kemungkinan jika setelah lulus nanti mereka akan bekerja di perusahaan China.

Peneliti juga menanyakan kepada 38 mahasiswa yang menjadi responden tentang keinginan untuk bekerja di perusahaan China setelah lulus nantinya. Dan hasil yang didapat 
adalah sebanyak 29 mahasiswa (76,3\%) ingin bekerja di perusahaan China setelah lulus nantinya, dan 9 Mahasiswa (23,7\%) tidak memiliki keinginan untuk bekerja di perusahaan China.

Sebagian besar mahasiswa memiliki keinginan untuk bekerja di perusahaan China, sehingga mereka menyatakan sangat perlu mempelajari shangwu kouyu untuk mempersiapkan diri bekerja di bidang bisnis setelah lulus nantinya sebagai bekal untuk mendukung keinginan mahasiswa bekerja di perusahaan China.

Tabel 3. Materi sesuai dengan bahan ajar

\begin{tabular}{|c|c|c|c|c|}
\hline \multirow{2}{*}{ NO } & \multirow{2}{*}{ MATERI } & \multicolumn{3}{|c|}{ Hasil } \\
\hline & & B & CB & TB \\
\hline 1. & $\begin{array}{c}\text { Kunjungan } \\
\text { pabrik }\end{array}$ & 16 & 21 & 1 \\
\hline 2. & Pertemuan & 24 & 13 & 1 \\
\hline 3. & Tentang produk & 22 & 15 & 1 \\
\hline 4. & Profil perusahaan & 23 & 14 & 1 \\
\hline 5. & $\begin{array}{l}\text { Pengiriman } \\
\text { barang }\end{array}$ & 19 & 18 & 1 \\
\hline 6. & $\begin{array}{c}\text { Metode } \\
\text { pembayaran }\end{array}$ & 25 & 12 & 1 \\
\hline 7. & $\begin{array}{l}\text { Pengemasan } \\
\text { barang }\end{array}$ & 16 & 18 & 4 \\
\hline 8. & Telepon bisnis & 28 & 9 & 1 \\
\hline 9. & Ekspor impor & 28 & 9 & 1 \\
\hline 10. & $\begin{array}{c}\text { Kontrak } \\
\text { Kerjasama }\end{array}$ & 31 & 6 & 1 \\
\hline 11. & Bisnis perjalanan & 24 & 13 & 1 \\
\hline 12. & Bersosialisasi & 30 & 7 & 1 \\
\hline 13. & Acara bisnis & 17 & 20 & 1 \\
\hline 14. & Perdagangan & 22 & 15 & 1 \\
\hline 15. & $\begin{array}{l}\text { Pemasaran dan } \\
\text { layanan } \\
\text { pelanggan }\end{array}$ & 28 & 9 & 1 \\
\hline 16. & $\begin{array}{l}\text { Frasa tempat } \\
\text { kerja umum }\end{array}$ & 16 & 21 & 1 \\
\hline 17. & Perekrutan & 21 & 16 & 1 \\
\hline 18. & Surat bisnis & 24 & 13 & 1 \\
\hline 19. & $\begin{array}{l}\text { Membangun } \\
\text { hubungan bisnis }\end{array}$ & 27 & 10 & 1 \\
\hline 20. & Jaminan & 16 & 20 & 2 \\
\hline 21. & Perbankan & 22 & 15 & 1 \\
\hline 22. & Kredit & 20 & 15 & 3 \\
\hline 23. & $\begin{array}{l}\text { Jenis organisasi } \\
\text { bisnis }\end{array}$ & 14 & 20 & 3 \\
\hline
\end{tabular}

Berdasarkan tabel 3. diatas, paling banyak mahasiswa menyatakan bahwa materi tentang kontrak kerjasama sangat dibutuhkan, selain itu materi tentang bersosialisasi, telepon bisnis, ekspor impor dan materi tentang pemasaran dan layanan pelanggan juga tidak kalah dibutuhkannya untuk diajarkan. Selain materi materi tersebut, mahasiswa juga berharap nantinya akan disisipkan materi bagaimana membuat surat lamaran kerja dalam bahasa mandarin. Karena, surat lamaran kerja termasuk dalam hal hal penting yang harus disiapkan ketika akan mulai bekerja.

Dalam pembelajaran shangwu kouyu selama ini, mahasiswa mengatakan bahwa pembelajaran sudah cukup baik karena disertai dengan praktik. Untuk pembelajaran shangwu kouyu kedepannya, mahasiswa berharap adanya pembaharuan materi agar sesuai dengan kebutuhan atau materi yang mengacu pada perkembangan bisnis di China.

\section{SIMPULAN}

Materi yang digunakan dalam pembelajaran selama ini hanya sebatas "cukup" untuk mendukung mahasiswa bekerja di bidang bisnis setelah lulus nantinya, bahkan bisa dikatakan kurang karena hanya mempelajari 3 materi yang belum pasti digunakan di lapangan kerja. Perlu adanya bahan ajar yang tepat untuk diberikan kepada mahasiswa, yaitu bahan ajar yang yang memuat materi komprehensiv tingkat menengah dan sesuai dengan kebutuhan lapangan kerja yang sebenarnya.

Berdasarkan hasil pengisian angket/kuisioner, stake holde menyatakan, terdapat 8 materi utama yang paling dibutuhkan untuk mahasiswa prodi pendidikan bahasa Mandarin UNNES, yaitu materi kunjungan pabrik, materi pertemuan, materi telepon bisnis, materi kontrak kerjasama, materi bersosisalisai, materi acara bisnis, materi perdagangan dan materi surat bisnis alumni mentayakan terdapat 5 materi utama yang paling dibutuhkan, yaitu materi metode pembayaran materi pengiriman barang, materi pengemasan barang, materi ekspor impor, dan materi kontrak kerjasama dan 2 materi tambahan yaitu pajak dan produksi. Mahasiswa menyatakan terdapat 5 materi utama yang paling dibutuhkan, yaitu materi tentang kontrak kerjasama, materi bersosialisasi, materi 
telepon bisnis, materi ekspor impor serta materi tentang pemasaran dan layanan pelanggan.

\section{DAFTAR PUSTAKA}

Ilyas. (2016). PENDIDIKAN KARAKTER MELALUI HOMESCHOOLING. Journal of Nonformal Education, Vol. 2 No 1. Semarang : Universitas Negeri Semarang

Saebani, B.A. (2008). Metode Penelitian. Bandung: Pustaka Setia.

Siyoto, Sandu. (2015). Dasar Metodologi Penelitian. Yogyakarta: Literasi Media Publishing

Sugiyono. (2011). Metode Penelitian Kuantitatif Kualitatif dan R\&D. Bandung: Alfabeta

Wildia, dkk.(2018).Makalah kriteria dan teknik pemeriksaan keabsahan data. Pontianak: IAIN Pontianak

晓琪，李, dkk. (2009). 新丝路 - 中级速成商务汉语 II.

Peking : Universitas Peking

雅玲，孫，dkk.(2010). SITUATIONAL CHINESE

Business and Business Travel. Taiwan: Bookman Books, Ltd.

https://www.bkpm.go.id/images/uploads/file_siara n_pers/Paparan_Indonesia_TW_IV_-

_2017_Kepala.pdf ( diakses pada 9 Januari 2020 ) 